\title{
A Final Reply to Hutchison and Loomis
}

\author{
Dennis R. Proffitt, Jeanine Stefanucci, Tom Banton, and William Epstein \\ University of Virginia
}

\begin{abstract}
While acknowledging that their design and methods were different from the original Proffitt, Stefanucci, Banton, and Epstein (2003) study, Hutchison and Loomis (H\&L) continue to argue that their findings qualify our account of energetic influences on distance perception. This reply provides a brief and focused discussion of the methodological differences between their study and ours and why these differences were likely responsible for the different results. It is also argued that the measures employed by H\&L are assessments of apparent location, not apparent distance.

Keywords: distance perception, spatial perception, energetics, perceived location, intention
\end{abstract}

\begin{abstract}
Aunque Hutchison y Loomis (H\&L) reconozcan que el diseño y los métodos de su estudio difieren de los del trabajo original de Proffit, Stefanucci, Banton y Epstein (2003), siguen indicando que sus resultados cuestionan nuestra explicación sobre la influencia del consumo energético en la percepción de la distancia. Esta replica proporciona una discusión breve centrada en las diferencias metodologicas existentes entre su estudio y el nuestro, y también sobre por qué tales diferencias son las causas más probables de las diferencias en los resultados. Se indica, además, que las medidas empleadas por H\&L son adecuadas para evaluar la localización pero no la distancia aparente.

Palabras clave: percepción de la distancia, percepción espacial, consumo energético, localización percibida, finalidad
\end{abstract}

Correspondence: Dennis Proffitt, Department of Psychology, University of Virginia, P.O. Box 400400, Charlottesville, VA 22904 (USA). Office Phone: 434-924-0655. Fax: 434-982-4750. E-mail: drp@ virginia.edu 
In their reply, Hutchison and Loomis (this issue) acknowledge that their design and methodology were different from ours; however, they continue to argue that their findings cast doubts on the robustness of our findings of energetic influences on distance perception. Their claim remains questionable. We continue to believe that the differences in our methodology and theirs could account for the differences in findings. In addition, the theoretical motivation for their studies remains problematic. This reply will be brief.

\section{Methodological Differences}

In their reply, H\&L commented on three of our methodological criticisms. Each will be addressed in turn.

\section{Criticism 1}

H\&L agree that their use of a within-participants design likely caused participants to guess that the backpack manipulation was supposed to influence their distance judgments. Providing participants with explicit expectations about an experiment's intent invites them to make cognitive corrections.

\section{Criticism 2}

H\&L wonder why our backpack manipulation should have an influence even though our participants never walked to the targets. By our account of energetic influences on spatial perception, people are influenced by the effort associated with intended actions. In the case of the ground plane, we believe that the natural default is to view its layout relative to walking effort. After all, the most common action directed at the ground is, by far, walking. We have repeatedly found that manipulations of walking effort influence the perceived layout of the ground even if people do not actually walk the relevant extent (Bhalla, \& Proffitt, 1999; Proffitt, Bhalla, Gossweiler, \& Midgett, 1995; Proffitt, Stefanucci, Banton, \& Epstein, 2003; Stefanucci, Proffitt, Banton, \& Epstein, 2005). We have, of course, also found that effort for walking influences apparent distance when people do anticipate walking to targets (Witt, Proffitt, \& Epstein, 2004).

On the other hand, whenever we evoked anticipations that some action other than walking would be performed after the distance judgment, manipulations of walking effort did not influence apparent distance (Witt, et al., 2004). For example, Witt et al. had participants make distance judgments after a manipulation of walking effort. Those participants who anticipated that they would next walk to the target were influenced by the manipulation, whereas those who anticipated that they would next throw a bean bag to the target location were not. H\&L's participants made verbal distance estimates with the explicit expectation that they would next make size judgments, which would then be followed by their walking away from the target. We would not expect the backpack to influence their distance judgments in this situation.

\section{Criticism 3}

H\&L suggested that, since their field of view manipulation had a significant effect, a lack of a significant result for the backpack manipulation casts doubt on the robustness of the backpack effect. Given the problems with H\&L's design - especially that the distance judgments were followed by tasks other than walking - it is unclear what conclusions are warranted.

\section{Theoretical Issues}

In their reply, $\mathrm{H} \& \mathrm{~L}$ defend their indirect blind walking measure as being a valid measure of perceived distance. We remain unconvinced. In our initial reply to their article was stated the following: "Not only is triangulated walking postperceptual, it is not even known whether its performance relies on a perception of distance at all. Triangulated walking requires the spatial-updating of a target's location. Location and distance are not the same. A location is a point; a distance is an extent. A location can be pointed to; a distance cannot." This distinction between location and distance was not addressed in their reply and it remains a critical issue.

H\&L argued that indirect blind walking should be construed as a measure of apparent distance because it covaries tightly with other measures of perceived distance (Philbeck \& Loomis, 1997). This covariation among measures may be due to their sharing a common perception or to their sharing common informational bases. In our initial reply, we introduced the notion that a target's angular elevation relates to both its distance and its location to highlight the fact that apparent distance and location share common informational bases. (It was not our intent to suggest that indirect blind walking was controlled exclusively by this optical variable as H\&L imply in their reply.)

Just as it is important to distinguish between the location of a target and its egocentric distance, it is also important to distinguish between information and perception. Measures of apparent location and distance ought to be coupled because they share common informational bases. They are, however, distinctly different perceptions; location is a point, whereas distance is an extent. At least in some situations employing visually directed blind walking tasks, perceived allocentric distances and locations have been found to be dissociable (Kudoh, 2005). Had H\&L found that their backpack manipulation influenced verbal reports but not indirect blind walking, then we would take this finding as suggestive of a dissociation between apparent distance - as measured by the verbal report - and apparent location - as measured by triangulated walking. 


\section{References}

Bhalla, M., \& Proffitt, D. R. (1999). Visual-motor recalibration in geographical slant perception. Journal of Experimental Psychology: Human Perception and Performance, 25, 10761096.

Hutchison, J.J. \& Loomis, J.M. (this issue). Does energy expenditure affect the perception of egocentric distance? A failure to replicate Experiment 1 of Proffitt, Stefanucci, Banton, and Epstein (2003).

Hutchison, J.J. \& Loomis, J.M. (this issue). Reply to Proffitt, Stefanucci, Banton, and Epstein.

Kudoh, N. (2005). Dissociation between visual perception of allocentric distance and visually directed walking of its extent. Perception, 34, 1399-1416.

Philbeck, J. W., \& Loomis, J. M. (1997). Comparison of two indicators of perceived egocentric distance under full-cue and reduced-cue conditions. Journal of Experimental Psychology: Human Perception and Performance, 23, 72-85

Proffitt, D.R., Bhalla, M., Gossweiler, R., \& Midgett, J. (1995). Perceiving geographical slant. Psychonomic Bulletin \& Review, 2, 409-428.

Proffitt, D.R., Stefanucci, J., Banton, T., \& Epstein, W. (2003). The role of effort in perceiving distance. Psychological Science, 14, 106-112.

Stefanucci, J.K., Proffitt, D.R., Banton, T., \& Epstein, W. (2005). Distances appear different on hills. Perception \& Psychophysics, 67, 1052-1060.

Witt, J.K., Proffitt, D.R., \& Epstein, W. (2004). Perceiving distance: A role of effort and intent. Perception, 33, 577-590.

Received May 1, 2006 Review received May 5, 2006 Accepted May 18, 2006 